\title{
Whereas short-term facilitation is presynaptic, intermediate-term facilitation involves both presynaptic and postsynaptic protein kinases and protein synthesis
}

\author{
Iksung Jin, ${ }^{1}$ Eric R. Kandel, ${ }^{1,2,3,4}$ and Robert D. Hawkins ${ }^{1,2,5}$ \\ ${ }^{1}$ Department of Neuroscience, Columbia University, New York, New York 10032, USA; ${ }^{2}$ New York State Psychiatric Institute, New York, \\ New York 10032, USA; ${ }^{3}$ Kavli Institute for Brain Science, New York, New York 10032, USA; ${ }^{4}$ Howard Hughes Medical Institute, \\ New York, New York 10032, USA
}

\begin{abstract}
Whereas short-term plasticity involves covalent modifications that are generally restricted to either presynaptic or postsynaptic structures, long-term plasticity involves the growth of new synapses, which by its nature involves both pre- and postsynaptic alterations. In addition, an intermediate-term stage of plasticity has been identified that might form a bridge between short- and long-term plasticity. Consistent with that idea, although short-term term behavioral sensitization in Aplysia involves presynaptic mechanisms, intermediate-term sensitization involves both pre- and postsynaptic mechanisms. However, it has not been known whether that is also true of facilitation in vitro, where a more detailed analysis of the mechanisms involved in the different stages and their interrelations is feasible. To address those questions, we have examined preand postsynaptic mechanisms of short- and intermediate-term facilitation at Aplysia sensory-motor neuron synapses in isolated cell culture. Whereas short-term facilitation by 1-min 5-HT involves presynaptic PKA and CamKII, intermediate-term facilitation by 10-min 5-HT involves presynaptic PKC and postsynaptic $\mathrm{Ca}^{2+}$ and CamKII, as well as both pre- and postsynaptic protein synthesis. These results support the idea that the intermediate-term stage is the first to involve both pre- and postsynaptic molecular mechanisms, which could in turn serve as some of the initial steps in a cascade leading to synaptic growth during long-term plasticity.
\end{abstract}

Synaptic plasticity and memory storage have stages that involve different types of mechanisms at different sites (Bailey et al. 2008). Short-term plasticity involves covalent modifications that are generally thought to be restricted to either presynaptic or postsynaptic structures (Kandel 2001; Malinow and Malenka 2002). By contrast, long-term plasticity involves the protein and RNA synthesis-dependent growth of new synapses, which by its nature involves both pre- and postsynaptic alterations (Bailey and Chen 1988a,b; Glanzman et al. 1990; Bailey et al. 1992; Martin et al. 1997; Ma et al. 1999; Toni et al. 1999; Bozdagi et al. 2000; De Roo et al. 2008). However, it is not clear how these different stages of plasticity are related. On the one hand, under some circumstances short- and long-term plasticity can be produced independently, suggesting that they may be induced in parallel (Emptage and Carew 1993). On the other hand, in both Aplysia and hippocampus an intermediate-term stage of plasticity has been identified that usually involves protein but not RNA synthesis and structural alterations but not synaptic growth, and therefore might form a bridge between short- and long-term plasticity (Ghirardi et al. 1995; Winder et al. 1998; Sutton and Carew 2000; Sutton et al. 2001; Kim et al. 2003; Li et al. 2005, 2009; Villareal et al. 2007). That idea in turn suggests that aspects of the different stages of plasticity may be induced in series, similar to the states in artificial "cascade" models of memory storage (Fusi et al. 2005).

Consistent with that idea, we have recently found that whereas short-term behavioral sensitization in Aplysia involves presynaptic mechanisms, intermediate-term sensitization in-

\footnotetext{
${ }^{5}$ Corresponding author.
}

E-mail rdh1@columbia.edu; fax (212)543-5474.

Article is online at http://www.learnmem.org/cgi/doi/10.1101//m.1949711. volves both pre- and postsynaptic molecular mechanisms (Antonov et al. 2010), which may in turn be some of the initial steps in a program or cascade leading to synaptic growth during long-term plasticity. However, it has not been known whether that is also true of facilitation in vitro, where a more detailed analysis of the mechanisms involved in the different stages and their interrelations is feasible. We have therefore now examined both pre- and postsynaptic mechanisms of short- and intermediateterm facilitation in isolated cell culture, which has many technical advantages for such studies. Application of different concentrations or durations of the modulatory transmitter 5-HT to Aplysia sensory-motor neuron synapses in culture can produce short-, intermediate-, or long-term facilitation (Montarolo et al. 1986; Rayport and Schacher 1986; Ghirardi et al. 1995), making it possible to examine the mechanisms of each form of plasticity in the same preparation. In addition, because there are no other neurons in the culture dish, one can rule out indirect effects of plasticity at other sites. Furthermore, because both sides of the synapses are accessible to substances injected into the cell bodies, one can selectively manipulate pre- or postsynaptic mechanisms to investigate their contributions and possible interactions.

We have examined facilitation induced by either a single brief 5-HT exposure $(1 \mathrm{~min})$ or a more prolonged 5-HT exposure (10 min) at rested or depressed sensory-motor neuron synapses. Previous studies have found that short-term facilitation by 1-min 5-HT involves covalent modifications but does not require protein synthesis (Montarolo et al. 1986; Martin et al. 1997). By contrast, facilitation by 10-min 5-HT involves both covalent modifications and protein synthesis (Li et al. 2005; Villareal et al. 2007), suggesting that it represents a form of intermediate-term facilitation. However, the relative contributions of pre- and postsynaptic mechanisms have not been fully explored with either protocol. Our results suggest that whereas short-term facilitation 
by 1-min 5-HT involves presynaptic PKA and CamKII, intermediate-term facilitation by 10 -min 5 -HT involves presynaptic PKC and postsynaptic $\mathrm{Ca}^{2+}$ and CamKII, as well as both pre- and postsynaptic protein synthesis. These results in culture are generally similar to those from experiments on short- and intermediateterm behavioral sensitization in a semi-intact preparation (Antonov et al. 2010), and suggest that not only the specific kinases involved but also their site of action depends on the stage of facilitation. In addition, they support the idea that the intermediate-term stage is the first to involve both pre- and postsynaptic molecular mechanisms.

\section{Results}

We examined pre- and postsynaptic mechanisms of facilitation by either 1-min, $50 \mu \mathrm{M}$ 5-HT or 10-min, 10 or $20 \mu \mathrm{M}$ 5-HT in sensorymotor neuron cocultures. In most cases we applied the 5-HT after a single pretest to minimize synaptic depression by the test stimulation. Ten minute, $20 \mu \mathrm{M} 5$-HT produced larger facilitation than either 10-min, $10 \mu \mathrm{M}$ 5-HT or 1-min, $50 \mu \mathrm{M} 5$-HT, but facilitation with each protocol lasted $>30$ min after the beginning of washout of the 5-HT $(P<0.01$ in each case) compared with test-alone controls, which undergo homosynaptic depression (Fig. 1).

\section{Presynaptic mechanisms of short-term facilitation by 1 -min $5-\mathrm{HT}$}

Facilitation by 1 -min 5 -HT was significantly reduced by the PKA inhibitor KT5720 $(10 \mu \mathrm{M})\left(F_{(1,60)}=7.40, P<0.01\right.$ for the drug $\times$ 5 -HT interaction overall) or the CamKII inhibitor KN93 $(5 \mu \mathrm{M})$ $\left(F_{(1,60)}=4.08, P<0.05\right)$, but not by the broad-spectrum PKC inhibitor Go6983 (2 $\mu \mathrm{M})$ (Fig. 2A1). As controls, none of the drugs had significant effects on test-alone homosynaptic depression or
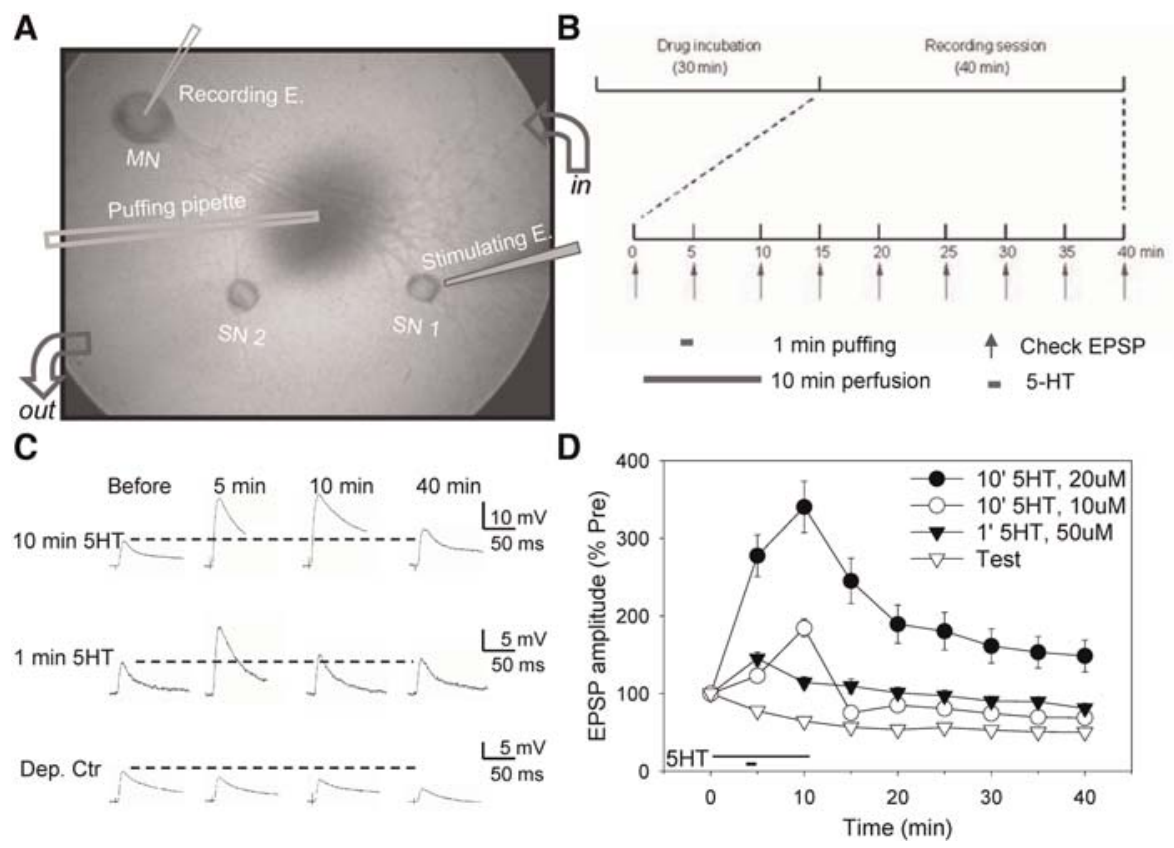

Figure 1. Facilitation by 1 - or $10-\mathrm{min} 5-\mathrm{HT}$ in isolated cell culture. $(A)$ The experimental preparation. (B) The general protocol (see the text for details). (C) Examples of EPSPs in representative experiments with 1-min 5-HT, 10-min 5-HT, or test-alone control. (D) The average change in the EPSP in all of the no-drug (control) experiments with 1-min 5-HT $(n=18), 10 \mathrm{~min}, 10 \mu \mathrm{M} \mathrm{5-HT}(n=18), 10 \mathrm{~min}$, $20 \mu \mathrm{M} 5$-HT $(n=20)$, and test-alone control $(n=18)$. There was a significant overall effect of group $\left(F_{(3,70)}=31.76, P<0.001\right)$ in a two-way ANOVA with one repeated measure (time). The data have been normalized to the value on the pretest in each experiment, and the error bars indicate the SEM. the pretest EPSP, compared with DMSO control. These results suggest that short-term facilitation by 1-min 5-HT involves PKA and CamKII but not PKC. To examine the site of action of the kinases, we injected inhibitors into the sensory neuron or the motor neuron (Fig. 2A2). Injection of a peptide inhibitor of PKA (PKA 6-22, $500 \mu \mathrm{M}$ in the electrode) into the sensory neuron significantly reduced the facilitation $\left(F_{(1,28)}=7.12, P<0.05\right.$ compared with vehicle control overall). Similarly, injection of a peptide inhibitor of CamKII (CamKII 281-309, $500 \mu \mathrm{M}$ in the electrode) into the sensory neuron also reduced the facilitation $\left(F_{(1,28)}=5.25, P<\right.$ 0.05). Injection of another peptide inhibitor of CamKII with a different mode of action ([Ala $\left.{ }^{286}\right]$-CamKII 281-301, $500 \mu \mathrm{M}$ in the electrode) produced similar results (data not shown). By contrast, injection of the $\mathrm{Ca}^{2+}$ chelator BAPTA (200 mM in the electrode) into the motor neuron had no significant effect. None of the with vehicle control. These results suggest that facilitation by 1-min 5-HT at nondepressed synapses involves presynaptic PKA and CamKII, but not postsynaptic $\mathrm{Ca}^{2+}$.

We next examined mechanisms of facilitation by 1-min 5-HT at depressed synapses. Stimulating the sensory neuron 10 times at 1-min intervals produced depression of the sensory-motor neuron EPSP to about $35 \%$ of pretest, followed by partial recovery during continued testing over the next $40 \mathrm{~min}$ (Fig. 2B1). One-minute 5 -HT produced rapid facilitation of the depressed EPSP, which The PKC inhibitor Go6983 significantly reduced the facilitation $\left(F_{(1,22)}=4.53, P<0.05\right.$ compared with 5 -HT control), with no significant effect on the depression or the pretest EPSP. To examine the site of action of PKC, we injected a peptide inhibitor of conelectrode) into the sensory or motor neuron. Injecting the inhibitor into the sensory neuron significantly reduced facilitation of the depressed EPSPs $\left(F_{(1,10)}=5.53\right.$, $P<0.05$ compared with vehicle control), with no significant effect on the depression or the pretest EPSP (Fig. 2B2). By contrast, injecting the inhibitor into motor neuron had no significant effect on facilitation, or on depression or the pretest EPSP (Fig. 2B3). These results indicate that facilitation at depressed synapses involves $\mathrm{PKC}$, in agreement with previous studies (Ghirardi et al. 1992; Byrne and Kandel 1996), and show that PKC acts in the presynaptic neuron. Thus, 1-min 5-HT produces short-term facilitation that is dependent on PKA and CamKII at nondepressed synapses or PKC at depressed synapse, but in either case the facilitation is presynaptic.

Pre- and postsynaptic mechanisms of intermediate-term facilitation by $10-\mathrm{min} 5-\mathrm{HT}$

We next examined facilitation by 10-min 5-HT and asked whether, like most other forms of intermediate-term facilitation (Ghirardi et al. 1995), it is protein synthesis dependent. Facilitation by $10-\mathrm{min}, 20 \mu \mathrm{M}$ 5-HT at nondepressed synapses was almost completely blocked by the protein synthesis inhibitor emetine 
A1

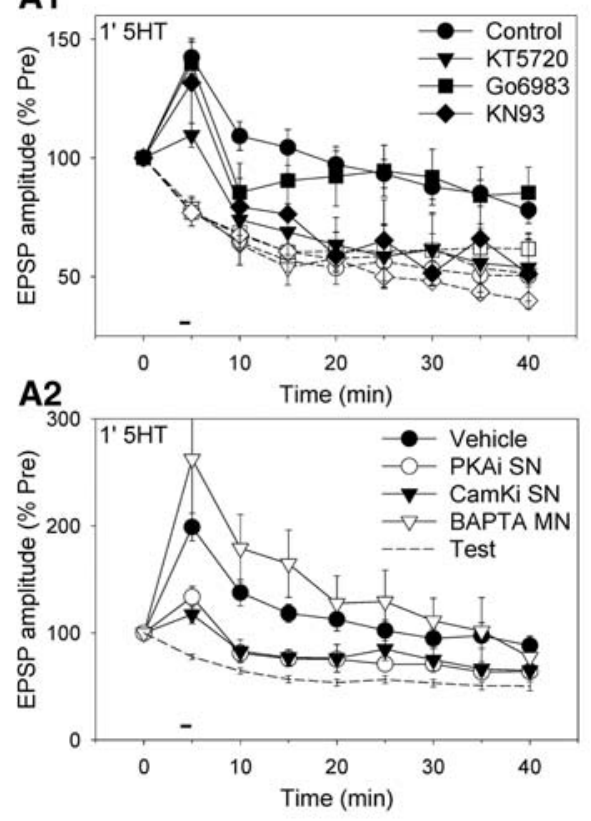

B1

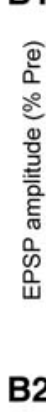

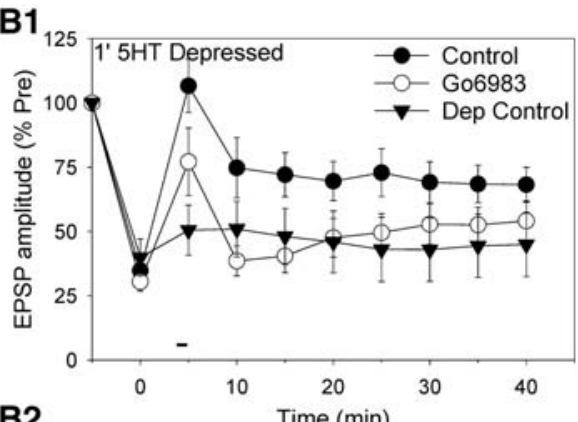

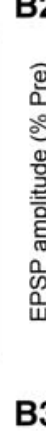
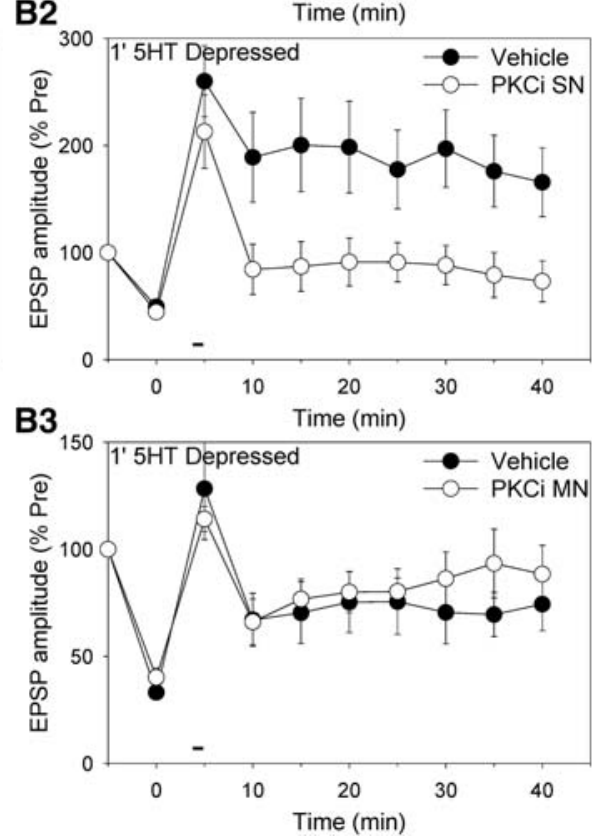

Figure 2. Facilitation by $1-\min 5-\mathrm{HT}$ at nondepressed synapses involves presynaptic PKA and CamKII, but not PKC or postsynaptic $\mathrm{Ca}^{2+}$, whereas facilitation at depressed synapses involves presynaptic PKC. (A1) The facilitation (black symbols) at nondepressed synapses was significantly reduced by the PKA inhibitor KT5720 $(n=6)$ or the CamKII inhibitor KN93 $(n=4)$ but not by the PKC inhibitor Go6983 $(n=8)$, compared with DMSO control $(n=18)$. Test-alone depression (white symbols) was not significantly affected by KT5720 $(n=6), \operatorname{Go6983}(n=5)$, or KN93 $(n=9)$, compared with control $(n=18)$. There was a significant overall drug $\times 5$ - $\mathrm{HT}$ interaction $\left(F_{(3,66)}=3.12, P<0.05\right)$. The average pretest values in this figure and Figures $2 \mathrm{~B} 1$ and $4 \mathrm{~A}$ (in $\mathrm{mV}$ ) were $11.6 \pm 0.8$ (control), $11.8 \pm 2.1$ (KT5720), $11.8 \pm 1.8$ (Go6983), and $11.5 \pm 1.5$ (KN93), not significantly different in a one-way ANOVA. (A2) Facilitation by 1-min 5-HT was significantly reduced by injection of peptide inhibitors of PKA $(n=7)$ or CamKII $(n=5)$ into the sensory neuron but not by injection of BAPTA $(n=4)$ into the motor neuron, compared with vehicle control $(n=16)$. There was a significant overall effect of inhibitor $\left(F_{(3,28)}=5.21, P<0.01\right)$. Results with vehicle injection into the sensory neuron or motor neuron were similar, and have been pooled. Test-alone control data are replotted from Figure 1D. (B1) Stimulation of the sensory neuron 10 times at 1-min intervals produced substantial depression of the EPSP, which recovered partially during continued testing over the next 40 min (depression control, $n=6$ ). One minute 5 -HT produced rapid and long-lasting facilitation at depressed synapses (control, $n=10)$, which was significantly reduced by the PKC inhibitor Go6983 $(n=9)$. There was a significant overall effect of group on the facilitation $\left(F_{(2,22)}=3.48, P<0.05\right)$. (B2) Facilitation at depressed synapses was significantly reduced by injection of a peptide inhibitor of PKC into the sensory neuron $(n=6)$, compared with vehicle control $(n=6)$. There was a significant overall effect of group $\left(F_{(1,10)}=5.53\right.$, $P<0.05)$. (B3) Facilitation at depressed synapses was not significantly reduced by injection of a peptide inhibitor of PKC into the motor neuron $(n=5)$, compared with vehicle control $(n=4)$.

the facilitation $\left(F_{(1,21)}=4.61, P<0.05\right.$ compared with vehicle control overall; Fig. 3B). Similarly, injection of hygomycin $\mathrm{B}$ into the motor neuron also reduced the facilitation $\left(F_{(1,21)}=\right.$ $5.29, P<0.05$ compared with vehicle). As controls, neither presynaptic nor postsynaptic injection of hygromycin B significantly affected the pretest EPSP. These results suggest that 10-min 5-HT produces protein synthesis-dependent intermediate-term facilitation, and show that protein synthesis is required in both the presynaptic and postsynaptic neurons.

We also examined the roles of PKA, PKC, and CamKII in facilitation during and after 10-min exposure to 10 or $20 \mu \mathrm{M} 5$-HT. The PKC inhibitor Go6983 and the CamKII inhibitor KN93 both reduced facilitation by either 10 or $20 \mu \mathrm{M} 5$-HT, which have therefore been pooled in Figure $4 \mathrm{~A}$ (overall $F_{(1,103)}=4.43, \quad P<0.05$ for the drug $\times 5$-HT interaction for Go6983 and $F_{(1,103)}=13.37, P<0.001$ for KN93). Furthermore, there was no significant difference in the effects of those inhibitors during and after the 5-HT (using log-transformed data to compare fold changes in the facilitation). However, the effect of the PKA inhibitor KT5720 depended on both the 5-HT concentration and test time $\left(F_{(1,103)}=7.53, P<0.01\right.$ for the drug $\times$ concentration $\times$ time interaction), due at least in part to a larger effect on facilitation during $10 \mu \mathrm{M}$ 5-HT $\left(F_{(1,66)}=2.99, \quad P<0.05\right.$ one-tail, inset). These results suggest that PKC and CamKII are involved in facilitation by $10-\mathrm{min} 5 \mathrm{HT}$, and that PKA contributes importantly only at early times and lower concentrations of 5-HT.

Injection of the peptide inhibitor PKC(19-31) into the sensory neuron significantly reduced facilitation by 10-min, $20 \mu \mathrm{M}$ 5-HT $\quad\left(F_{(1,32)}=6.66\right.$, $P<0.05$ compared with vehicle control overall), whereas injection of peptide inhibitors of PKA or CamKII into the sensory neuron did not have significant effects (Fig. 4B). By contrast, the facilitation was significantly reduced by injection of a peptide inhibitor of CamKII into the motor neuron $\left(F_{(1,58)}=6.20, P<0.05\right.$ compared with vehicle control overall;

$(100 \mu \mathrm{M})\left(F_{(1,18)}=8.60, P<0.01\right.$ for the drug $\times 5$-HT interaction overall; Fig. 3A). As controls, emetine did not have significant effects on test-alone homosynaptic depression or the pretest EPSP. We examined the site of the protein synthesis by injecting into the sensory or motor neuron an inhibitor with low membrane permeability, hygromycin B. Injection of hygromycin B (200 mg/ $\mathrm{mL}$ in the electrode) into the sensory neuron significantly reduced
Fig. 4C). The facilitation was also significantly reduced by injection of BAPTA into the motor neuron $\left(F_{(1,58)}=9.06, P<0.01\right.$ with 10 or $20 \mu \mathrm{M} 5-\mathrm{HT})$, but not by injection of PKC(19-31) into that neuron. Results were similar during and after the 5-HT, except that presynaptic injection of the PKA inhibitor tended to reduce facilitation during but not after the 5-HT. None of the injections had significant effects on the pretest EPSP, compared 

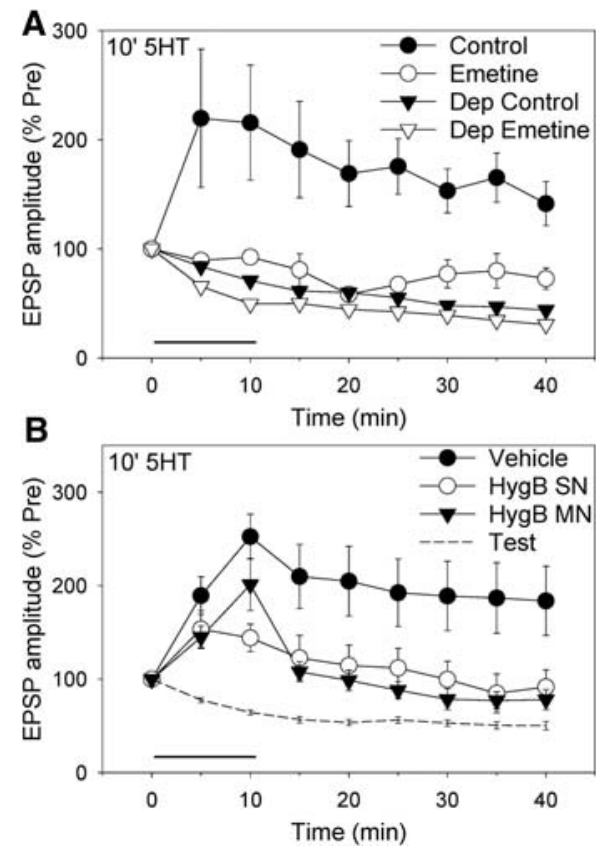

Figure 3. Facilitation by $10-\min 5-\mathrm{HT}$ involves both pre- and postsynaptic protein synthesis. (A) Facilitation by $20 \mu \mathrm{M} 5$-HT (circles) was significantly reduced by the protein synthesis inhibitor emetine $(n=5)$ compared with ASW control $(n=6)$. Test-alone depression (inverted triangles) was not significantly affected by emetine $(n=7)$ compared with control $(n=4)$. There was a significant overall drug $\times 5$ - HT interaction $\left(F_{(1,18)}=8.60, P<0.01\right)$. The average pretest values (in $\mathrm{mV}$ ) were $13.7 \pm 3.7$ (control) and $17.4 \pm 3.0$ (emetine), not significantly different. $(B)$ The facilitation was significantly reduced by injection of the protein synthesis inhibitor hygromycin B into either the sensory neuron $(n=6)$ or the motor neuron $(n=6)$ compared with vehicle control $(n=12)$. Results with vehicle injection into the sensory neuron or the motor neuron were similar, and have been pooled. There was a significant overall effect of group $\left(F_{(2,21)}=3.71, P<0.05\right)$. The average pretest values (in $\mathrm{mV}$ ) were $13.3 \pm 2.2$ (vehicle), $8.7 \pm 3.0$ (Hyg B SN), and $9.8 \pm 3.1$ (Hyg B MN), not significantly different.

with vehicle control. These results suggest that intermediate-term facilitation by 10-min 5HT involves PKC, but not PKA or CamKII, in the presynaptic neuron. In addition, it involves $\mathrm{Ca}^{2+}$ and CamKII, but not conventional or novel PKC, in the postsynaptic neuron. Because PKC(19-31) does not inhibit atypical PKC (Liu et al. 2000), these experiments did not address the possible role of that isoform in the postsynaptic neuron.

Not only does facilitation by 10-min 5-HT involve additional mechanisms (presynaptic PKC and postsynaptic $\mathrm{Ca}^{2+}$ and CamKII) compared with facilitation by 1 -min $5 \mathrm{HT}$, the later part (25-40 min) of the facilitation does not involve presynaptic PKA and CamKII (Fig. 4B), even though those kinases contribute to the same part of facilitation after 1-min 5HT (Fig. 2A2). These results suggest that the PKA and CamKII pathways are somehow inactivated by the additional 5-HT exposure. Previous evidence suggested that prolonged exposure to 5-HT may act to inhibit 5-HT receptor-coupled adenylyl cyclase (Sugita et al. 1992, 1997). One possible reason would be that enhanced spontaneous transmitter release during prolonged exposure to $5 \mathrm{HT}$ (Jin et al. 2007,2008 ) may activate presynaptic type II or III metabotropic glutamate receptors, which are negatively coupled to adenylyl cyclase. Consistent with that idea, an inhibitor of type II and III metabotropic glutamate receptors, LY341495 $(1 \mu \mathrm{M})$, significantly enhanced facilitation by $10-\mathrm{min}, 20 \mu \mathrm{M} 5-\mathrm{HT} \quad(P<0.05$ compared with DMSO control overall) (Fig. 4D). Moreover, that enhancement increased during and after the 5-HT exposure, while the contribution of presynaptic PKA was decreasing (Fig. 4B). As a control, LY341495 did not significantly affect the pretest EPSP. These results suggest that increased transmitter release during the facilitation may stimulate presynaptic type II or III metabotropic glutamate receptors, which feed back to inhibit the PKA pathway.

\section{Discussion}

In agreement with previous studies of the roles of PKA and PKC during facilitation at Aplysia sensory-motor neuron synapses (Byrne and Kandel 1996), we have found that facilitation by 1-min 5-HT at rested synapses involves PKA but not PKC, whereas facilitation by 1 -min $5 \mathrm{HT}$ at depressed synapses or by $10-\mathrm{min}$ 5 -HT at rested synapses involves PKC but not PKA. Somewhat surprisingly, we have found that CamKII also plays an important role during facilitation by either 1- or 10-min 5-HT. Similarly, CamKII plays an important role in facilitation during sensitization by one or four tail shocks in a reduced siphon-withdrawal preparation (Antonov et al. 2010). Previous studies have found that CamKII is present in Aplysia nervous tissue (Saitoh and Schwartz 1983, 1985) and that a CamKII inhibitor, KN62, reduces facilitation at sensory-motor neuron synapses (Nakanishi et al. 1997). However, KN62 also affected the baseline EPSP, complicating an interpretation of its effect on facilitation, and the possible role of CamKII has been studied very little since those initial studies. We have now obtained similar results with three additional CamKII inhibitors (KN93, CamKII 281-309, and [Ala ${ }^{286}$ ]CamKII 281-301), none of which had significant effects on the baseline EPSP. In addition, the inhibitors we have used are thought to be more specific than KN62 and each has a different mode of action, making nonspecificity of their effects seem unlikely. Thus, our results suggest that CamKII makes an important contribution to the facilitation.

We have also examined the pre- and postsynaptic roles of the kinases, which in some cases have not previously been investigated. We have found that presynaptic PKA and CamKII contribute to facilitation by 1 - but not 10-min 5 -HT at rested synapses. Presynaptic CamKII is also involved in all of the same effects as presynaptic PKA (including spike broadening) during sensitization in the siphon-withdrawal preparation (Antonov et al. 2010), suggesting a possible linkage between the two preynaptic kinase pathways. There are several ways in which PKA is known to affect the CamKII pathway in this and other systems (Saitoh and Schwartz 1983, 1985; Edmonds et al. 1990; Blitzer et al. 1998; Chang et al. 2000), and CamKII might also affect the PKA pathway or the two kinases might phosphorylate common substrates. In addition, we found that postsynaptic $\mathrm{Ca}^{2+}$ and CamKII contribute to facilitation by 10 -min but not 1 -min 5-HT, similar to the roles of postsynaptic $\mathrm{Ca}^{2+}$ and CamKII in sensitization by four but not one shocks in the siphon-withdrawal preparation (Antonov et al. 2010).

We also investigated the pre- and postsynaptic roles of PKC. As in mammals, PKC in Aplysia has three isoforms: a conventional form (Apl I) that requires diacylglycerol and $\mathrm{Ca}^{2+}$ for its activation, a novel form (Apl II) that requires diacylglycerol but not $\mathrm{Ca}^{2+}$, and an atypical form (Apl III) that requires neither (Kruger et al. 1991; Bougie et al. 2009). We injected the pseudosubstrate PKC(19-31), which inhibits conventional and novel but not atypical isoforms (Sossin and Schwartz 1992; Liu et al. 2000). Presynaptic injection of PKC(19-31) blocked facilitation by 1-min 5-HT at depressed synapses and facilitation by 10- min 5-HT at rested synapses, whereas postsynaptic injection of PKC(19-31) did not block either. These results are consistent 

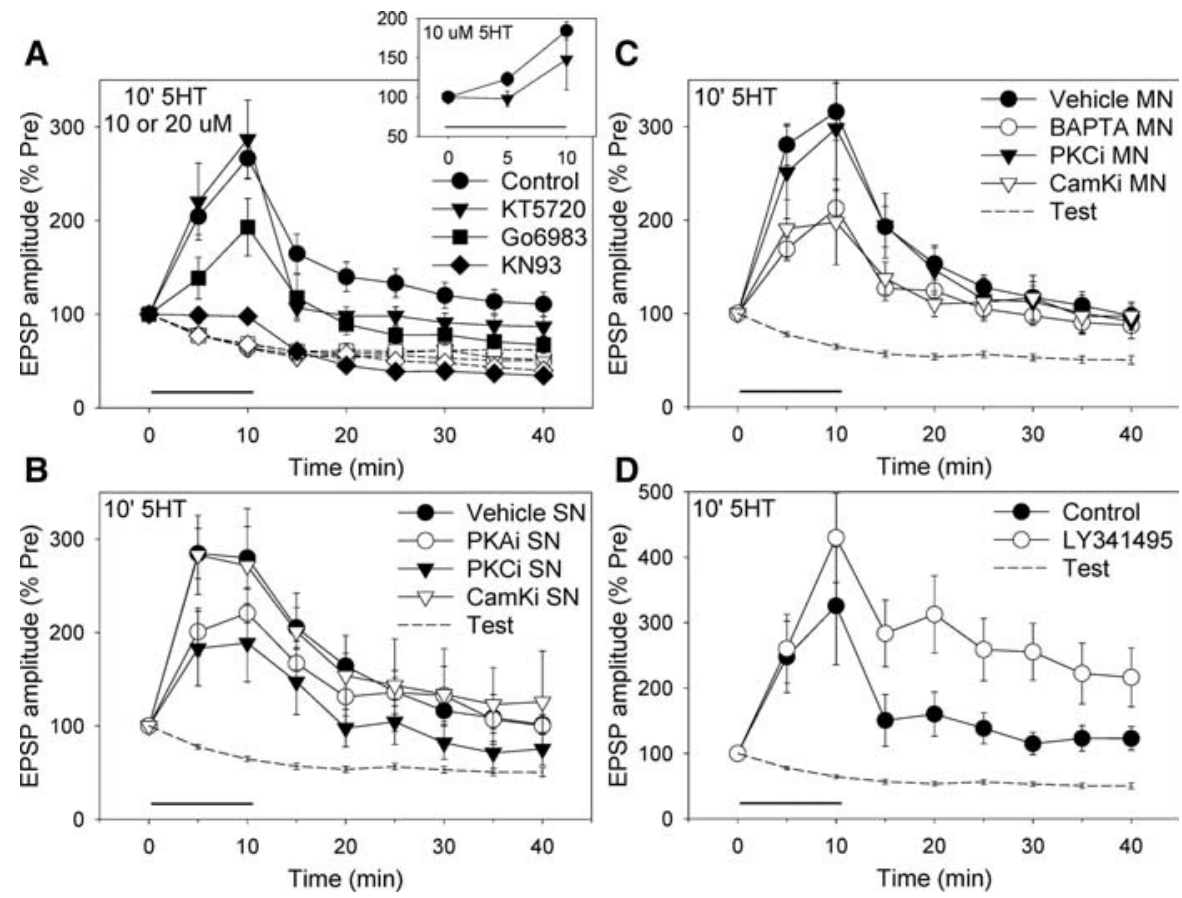

Figure 4. Facilitation by 10-min 5-HT at nondepressed synapses involves presynaptic PKC, postsynaptic $\mathrm{Ca}^{2+}$ and CamKII, and type II or III metabotropic glutamate receptors. $(A)$ Facilitation by 10 or $20 \mu \mathrm{M} 5$-HT (which have been pooled_-black symbols) was significantly reduced by the PKC inhibitor Go6983 $(n=14)$ or the CamKII inhibitor KN93 $(n=10)$ but not by the PKA inhibitor KT5720 $(n=15)$, compared with DMSO control $(n=38)$. Test-alone depression (white symbols) is replotted from Figure 2A1. There was a significant overall drug $\times 5$-HT interaction $\left(F_{(6,103)}=4.41, P<0.001\right)$. KT5720 had a greater effect on facilitation during $10 \mu \mathrm{M} \mathrm{5-HT} \mathrm{(} n=6$ and 18, insert). (B) Facilitation by $20 \mu \mathrm{M}$ 5-HT was significantly reduced by presynaptic injection of a peptide inhibitor of PKC $(n=$ 8 ) but not by peptide inhibitors of PKA $(n=5)$ or CamKII $(n=6)$, compared with vehicle control $(n=19)$. There was a significant overall group $\times$ vehicle/inhibitor interaction $\left(F_{(2,32)}=2.85, P<\right.$ 0.05 one-tail). The average pretest values for experiments with presynaptic injections in this figure and Figures $2 \mathrm{~A} 2$ and 2B2 (in $\mathrm{mV}$ ) were $6.8 \pm 1.0$ (vehicle), $10.7 \pm 2.1$ (PKA inhibitor), $7.4 \pm 2.2$ (PKC inhibitor), and 9.2 \pm 3.2 (CamKII inhibitor), not significantly different. (C) The facilitation was significantly reduced by postsynaptic injection of BAPTA $(n=22)$ or a peptide inhibitor of CamKII $(n=5)$ but not by a peptide inhibitor of PKC $(n=7)$, compared with vehicle control $(n=34)$. There was a significant overall group $\times$ vehicle/inhibitor interaction $\left(F_{(4,58)}=3.76, P<0.01\right)$. The average pretest values for experiments with postsynaptic injections in this figure and Figure $2 \mathrm{~A} 2$ and $2 \mathrm{~B} 3$ (in $\mathrm{mV}$ ) were $6.8 \pm 0.7$ (vehicle), $5.6 \pm 0.9$ (BAPTA), $6.5 \pm 1.1$ (PKC inhibitor), and $7.0 \pm 3.0$ (CamKII inhibitor), not significantly different. (D) The facilitation was significantly enhanced by the type II and III mGluR antagonist LY341495 ( $n=7)$ compared with DMSO control $(n=6)$. There was a significant overall effect of group $\left(F_{(1,11)}=3.97, P<0.05\right.$ one tail). The average pretest values (in $\mathrm{mV}$ ) were $12.9 \pm 4.2$ (control) and $9.9 \pm 2.3$ (LY341495), not significantly different.

with previous studies suggesting that presynaptic Apl II plays a role in facilitation by brief application of 5-HT to depressed synapses (Manseau et al. 2001) and by 5-min application of 5-HT to rested synapses (Zhao et al. 2006). They do not address the possible role of postsynaptic Apl III, which is important for facilitation of the glutamate response during 10-min application of 5-HT to isolated motor neurons (Villareal et al. 2009). However, unlike results from isolated motor neurons (Fulton et al. 2008; Villareal et al. 2009), our results suggest that postsynaptic Apl I and II do not play important roles during synaptic facilitation by 10 -min 5-HT. Thus, facilitation at synapses and isolated motor neurons may involve somewhat different mechanisms.

More generally, our results suggest that not only the specific kinases involved but also their site of action depends on the duration of 5-HT exposure. Furthermore, whereas facilitation with a short application of 5-HT is presynaptic, facilitation with a longer 5-HT exposure involves both presynaptic (PKC) and postsynaptic $\left(\mathrm{Ca}^{2+}\right.$ and CamKII) mechanisms. These results are generally similar to those during sensitization by one or four tail shocks (Antonov et al. 2010) except that in cell culture the stronger protocol (10-min 5-HT) involves presynaptic PKC rather than PKA and CamKII, in agreement with previous studies (Byrne and Kandel 1996).

Also in agreement with previous studies (Villareal et al. 2007), facilitation by 10 -min 5 -HT involves protein synthesis, like intermediate-term facilitation with most other protocols at sensory-motor neuron synapses. However, although intermediate-term facilitation with other protocols involves either PKA and protein synthesis (Ghirardi et al. 1995) or PKC but not protein synthesis (Sutton and Carew 2000), facilitation by $10-\mathrm{min}$ 5-HT involves both PKC and protein synthesis. Thus, 10-min 5-HT may produce a novel form of intermediate-term facilitation. The facilitation requires protein synthesis even at the earliest time point (5 min), like facilitation of the glutamate response during 10-min application of 5-HT to isolated motor neurons (Villareal et al. 2007). Consistent with those results, we have found that facilitation of EPSPs by 10 -min 5 -HT involves rapid protein synthesis in the postsynaptic neuron. In addition, we have found that the facilitation also involves rapid protein synthesis in the presynaptic neuron, just as it involves presynaptic as well as postsynaptic protein kinases.

These results support the idea that the intermediate-term stage is the first stage to involve both pre- and postsynaptic molecular mechanisms. Those mechanisms could serve as early steps in a program leading to synaptic growth during long-term facilitation, which also involves both pre- and postsynaptic mechanisms coordinated by transynaptic signaling (Trudeau and Castellucci 1995; Kandel 2001; Sherff and Carew 2004; Cai et al. 2008; Li et al. 2009; Wang et al. 2009). That idea in turn raises a number of new questions about the stages and their interrelations. For example, how are the postsynaptic mechanisms recruited, and what signaling molecules are involved? One possibility is that the postsynaptic mechanisms are recruited in parallel with the presynaptic mechanisms by activation of pre- and postsynaptic 5HT receptors (Li et al. 2005; Fulton et al. 2008; Villareal et al. 2007, 2009). Alternatively, recent studies have found that activation of presynaptic 5-HT receptors enhances spontaneous release of glutamate, which then activates metabotropic glutamate receptors to recruit the postsynaptic mechanisms of intermediate-term facilitation (Jin et al. 2007, 2008) and initiate a cascade that may culminate in synaptic growth during long-term facilitation (Jin et al. 2010). Those findings could explain why homosynaptic potentiation by tetanic stimulation of the presynaptic neuron (Jin and Hawkins 2003) involves some of the same postsynaptic mechanisms as intermediate-term 
facilitation (metabotropic glutamate receptors, IP3, $\mathrm{Ca}^{2+}$, and CamKII) but different presynaptic mechanisms. These two possible modes of recruitment of the postsynaptic mechanisms are not mutually exclusive, and both could contribute or they could act synergistically.

\section{Materials and Methods}

Aplysia cocultures (an L7 gill motor neuron and one or two pleural sensory neurons) were prepared as described previously (Schacher 1985; Bao et al. 1997; Fig. 1A). L7 neurons were isolated from juvenile (1-3 g) animals, and sensory neurons were isolated from adults (70-120 g). All animals were purchased from the Howard Hughes Medical Institute mariculture facility, Miami, FL. The cell culture medium consisted of 50\% filtered hemolymph and 50\% L-15 medium (Flow Laboratories) supplemented with salts (Bao et al. 1997).

Four to $6 \mathrm{~d}$ after plating of the cells, the motor neuron was impaled with a microelectrode (10-20 megaohm) filled with 2.5 $\mathrm{M} \mathrm{KCl}$, and one of the sensory neurons was stimulated to produce an EPSP in the motor neuron. If there were two sensory neurons, the other one was not used. Because some forms of plasticity are affected if the sensory neuron is impaled with an intracellular electrode (Eliot et al. 1994), we used extracellular stimulation. The motor neuron was hyperpolarized $30 \mathrm{mV}$ below resting potential during the recording periods to allow measurement of the EPSP without postsynaptic action potentials. After $30 \mathrm{~min}$ of rest or drug incubation, the EPSP was tested once every $5 \mathrm{~min}$ for $40 \mathrm{~min}$. 5-HT was applied to the cultures either by puffing (50 $\mu \mathrm{M} 5$-HT with $0.2 \%$ fast green for $1 \mathrm{~min}$ before the second EPSP) or by perfusion (10 or $20 \mu \mathrm{M}$ for $10 \mathrm{~min}$ after the first EPSP) (Fig. 1B). In test-alone control experiments, the 5-HT was omitted. All experiments were performed at room temperature $\left(20^{\circ} \mathrm{C}-23^{\circ} \mathrm{C}\right)$ and the culture dish was continuously perfused at a rate of $0.5 \mathrm{~mL} / \mathrm{min}$ with $50 \%$ supplemented L-15 medium and $50 \%$ ASW. Drugs were included in the perfusion solution from the beginning of the 30-min rest period until the end of the experiment. Emetine (EMD Bioscience) was prepared as a stock solution in water and diluted in the perfusion medium before use. KT5720, KN93, Go6983 (Calbiochem) and LY341495 (Tocris) were prepared as stock solutions in DMSO and diluted to a final concentration of $0.1 \%$ DMSO. In those experiments, the control saline contained $0.1 \%$ DMSO.

In some experiments inhibitors were pressure injected into the sensory or motor neuron from a 3-6 megaohm electrode. The injection solution consisted of $0.5 \mathrm{M}$ potassium acetate, $10 \mathrm{mM}$ Tris- $\mathrm{HCl}$ to adjust the $\mathrm{pH}$ to $7.5,0.2 \%$ fast green to visualize the injection, and one of the following: PKA 6-22, PKC 19-31, CamKII 281-309, BAPTA, or hygromycin B (Calbiochem). In control experiments the vehicle solution was injected into the neuron. The electrode was then removed and replaced with a stimulating (sensory neuron) or recording (motor neuron) electrode, and the preparation was rested $30 \mathrm{~min}$ before the beginning of the experiment.

Drug or inhibitor experiments were interleaved with control experiments from the same culture batch, usually on the same day. The data were analyzed with two- or three-way ANOVAs with one repeated measure (time), followed by planned comparisons of the individual groups if there were more than two (Winer et al. 1991). The overall ANOVA results are reported in the figure legends and individual comparisons of interest are reported in the Results. Data with 10 and $20 \mu$ M 5-HT (Fig. 4A) were analyzed as a separate factor in the ANOVA, but were generally similar and have been combined in the figure. Data from the 10-min 5-HT experiments were first analyzed overall, followed by planned comparisons during (5-10 $\mathrm{min})$ and after (15-40 min) the 5-HT. Results during and after 5-HT were also compared with each other (using log-transformed data to compare fold changes in the facilitation) and were significantly different in only one condition (the KT5720 $\times$ concentration $\times$ time interaction in Fig. 4A). We have therefore not reported them separately in the other conditions.

\section{Acknowledgments}

This research was supported by MH26212, NS045108, MH045923, and the HHMI.

\section{References}

Antonov I, Kandel ER, Hawkins RD. 2010. Presynaptic and postsynaptic mechanisms of synaptic plasticity and metaplasticity during intermediate-term memory formation in Aplysia. J Neurosci 30: 5781-5791.

Bailey CH, Chen M. 1988a. Long-term memory in Aplysia modulates the total number of varicosities of single identified sensory neurons. Proc Natl Acad Sci 85: 2373-2377.

Bailey CH, Chen M. 1988b. Long-term sensitization in Aplysia increases the number of presynaptic contacts onto the identified gill motor neuron L7. Proc Natl Acad Sci 85: 9356-9359.

Bailey CH, Montarolo P, Chen M, Kandel ER, Schacher S. 1992. Inhibitors of protein and RNA synthesis block structural changes that accompany long-term heterosynaptic plasticity in Aplysia. Neuron 9: 749-758.

Bailey CH, Barco A, Hawkins RD, Kandel ER. 2008. Molecular studies of learning and memory in Aplysia and hippocampus: A comparative analysis of implicit and explicit memory storage. In Learning and memory: A comprehensive reference (ed. J Byrne). Elsevier, Oxford, UK.

Bao J-X, Kandel ER, Hawkins RD. 1997. Involvement of pre- and postsynaptic mechanisms in posttetanic potentiation at Aplysia synapses. Science 275: 969-973.

Blitzer RD, Connor JH, Brown GP, Wong T, Shenolikar S, Iyengar R, Landau EM. 1998. Gating of CamKII by cAMP-regulated protein phosphatase activity during LTP. Science 280: 1940-1942.

Bougie JK, Lim T, Farah CA, Manjunath V, Nagakura I, Ferraro GB, Sossin WS. 2009. The atypical protein kinase C in Aplysia can form a protein kinase M by cleavage. J Neurochem 109: 1129-1143.

Bozdagi O, Shan W, Tanaka H, Benson DL, Huntley GW. 2000. Increasing numbers of synaptic puncta during late-phase LTP: N-cadherin is synthesized, recruited to synaptic sites, and required for potentiation. Neuron 28: 245-259.

Byrne JH, Kandel ER. 1996. Presynaptic facilitation revisited: State and time dependence. J Neurosci 16: 425-435.

Cai D, Chen S, Glanzman DL. 2008. Postsynaptic regulation of long-term facilitation in Aplysia. Curr Biol 8: 920-925.

Chang DJ, Li XC, Lee YS, Kim HK, Kim US, Cho NJ, Lo X, Weiss KR, Kandel ER, Kaang BK. 2000. Activation of a heterologously expressed octopamine receptor coupled to adenylyl cyclase produces all the features of presynaptic facilitation in Aplysia sensory neurons. Proc Natl Acad Sci 97: 1829-1834.

De Roo M, Klauser P, Muller D. 2008. LTP promotes a selective long-term stabilization and clustering of dendritic spines. PLOS Biol 6: $1850-1860$.

Edmonds B, Klein M, Dale N, Kandel ER. 1990. Contributions of two types of calcium channels to synaptic transmission and plasticity. Science 250: $1142-1147$.

Eliot LS, Kandel ER, Hawkins RD. 1994. Modulation of spontaneous transmitter release during depression and posttetanic potentiation of Aplysia sensory-motor neuron synapses isolated in culture. J Neurosci 14: $3280-3292$.

Emptage NJ, Carew TJ. 1993. Long-term synaptic facilitation in the absence of short-term facilitation in Aplysia neurons. Science 262: 253-256.

Fulton D, Condro MC, Pearce K, Glanzman DL. 2008. The potential role of postsynaptic phospholipase $\mathrm{C}$ activity in synaptic facilitation and behavioral sensitization in Aplysia. J Neurophysiol 100: 108-116.

Fusi S, Drew PJ, Abbott LF. 2005. Cascade models of synaptically stored memories. Neuron 45: 599-611.

Ghirardi M, Braha O, Hochner B, Montarolo PG, Kandel ER, Dale N. 1992. Roles of PKA and PKC in facilitation of evoked and spontaneous transmitter release at depressed and nondepressed synapses in Aplysia sensory neurons. Neuron 9: 479-489.

Ghirardi M, Montarolo PG, Kandel ER. 1995. A novel intermediate stage in the transition between short- and long-term facilitation in the sensory to motor neuron synapses of Aplysia. Neuron 14: 413-420.

Glanzman DL, Kandel ER, Schacher S. 1990. Target-dependent structural changes accompanying long-term synaptic facilitation in Aplysia neurons. Science 249: 799-802.

Jin I, Hawkins RD. 2003. Presynaptic and postsynaptic mechanisms of a novel form of homosynaptic potentiation at Aplysia sensory-motor neuron synapses. J Neurosci 23: 7288-7297.

Jin I, Rayman JB, Puthanveettil S, Vishwasrao H, Kandel ER, Hawkins RD. 2007. Spontaneous transmitter release from the presynaptic sensory neuron recruits IP3 production in the postsynaptic motor neuron 
during the induction of intermediate-term facilitation in Aplysia. Soc Neurosci Abstr 429.13.

Jin I, Rayman JB, Puthanveettil S, Vishwasrao H, Kandel ER, Hawkins RD. 2008. Spontaneous transmitter release from the presynaptic neuron recruits postsynaptic mechanisms contributing to intermediate-term facilitation in Aplysia. Soc Neurosci Abstr 880.23.

Jin I, Udo H, Puthanveettil S, Rayman JB, Vishwasrao H, Kandel ER, Hawkins RD. 2010. Spontaneous transmitter release from the presynaptic neuron initiates a cascade of pre- and postsynaptic mechanisms for intermediate- and long-term facilitation and synaptic growth in Aplysia. Soc Neurosci Abstr 409.3.

Kandel ER. 2001. The molecular biology of memory storage: A dialogue between genes and synapses. Science 294: 1030-1038.

Kim J-H, Udo H, Li H-L, Toun TY, Chen M, Kandel ER, Bailey CH. 2003. Presynaptic activation of silent synapses and growth of new synapses contribute to intermediate and long-term facilitation in Aplysia. Neuron 40: $151-165$.

Kruger KE, Sossin WS, Sacktor TC, Bergold PJ, Beushausen S, Schwartz JH. 1991. Cloning and characterization of $\mathrm{Ca}(2+)$-dependent and $\mathrm{Ca}(2+)$-independent PKCs expressed in Aplysia sensory cells. J Neurosci 11: $2302-2313$

Li Q, Roberts AC, Glanzman DL. 2005. Synaptic facilitation and behavioral dishabituation in Aplysia: Dependence on release of $\mathrm{Ca}^{2+}$ from postsynaptic intracellular stores, postsynaptic exocytosis, and modulation of postsynaptic AMPA receptor efficacy. J Neurosci 25: 5623-5637.

Li HL, Huang BS, Vishwasrao H, Sutedja N, Chen W, Jin I, Hawkins RD, Bailey CH, Kandel ER. 2009. Dscam mediates remodeling of glutamate receptors in Aplysia during de novo and learning-related synapse formation. Neuron 61: $527-540$.

Liu K-P, Hsiung S-C, Adlersberg M, Sacktor T, Gershon MD, Tamir H. 2000. $\mathrm{Ca}^{2+}$-evoked serotonin secretion by parafollicular cells: Roles in signal transduction of phosphatidylinositol $3^{\prime}$-kinase, and the $\gamma$ and $\zeta$ isoforms of protein kinase C. I Neurosci 20: $1365-1373$.

Ma L, Zablow L, Kandel ER, Siegelbaum SA. 1999. Cyclic AMP induces functional presynaptic boutons in hippocampal CA3-CA1 neuronal cultures. Nat Neurosci 2: 24-30.

Malinow R, Malenka RC. 2002. AMPA receptor trafficking and synaptic plasticity. Annu Rev Neurosci 25: 103-126.

Manseau F, Fan X, Hueftlein T, Sossin W, Castellucci VF. 2001. $\mathrm{Ca}^{2+}$-independent protein kinase C Apl II mediates the serotonin-induced facilitation at depressed Aplysia sensorimotor synapses. J Neurosci 21: 1247-1256.

Martin KC, Casadio A, Zhu H, Yaping E, Rose JC, Chen M, Bailey CH, Kandel ER. 1997. Synapse-specific, long-term facilitation of Aplysia sensory to motor synapses: A function for local protein synthesis in memory storage. Cell 91: 927-938.

Montarolo PG, Goelet P, Castellucci VF, Morgan J, Kandel ER, Schacher S. 1986. A critical period of macromolecular synthesis in long-term heterosynaptic facilitation in Aplysia. Science 234: 1249-1254.

Nakanishi K, Zhang F, Baxter DA, Eskin A, Byrne JH. 1997. Role of calcium-calmodulin-dependent protein kinase II in modulation of sensorimotor synapses in Aplysia. J Neurophysiol 78: 409-416.

Rayport SG, Schacher S. 1986. Synaptic plasticity in vitro: Cell culture of identified Aplysia neurons mediating short-term habituation and sensitization. J Neurosci 6: 759-763.
Saitoh T, Schwartz JH. 1983. Serotonin alters the subcellular distribution of a Ca ${ }^{2+} /$ calmodulin-binding protein in neurons of Aplysia. Proc Natl Acad Sci 80: 6708-6712.

Saitoh T, Schwartz JH. 1985. Phosphorylation-dependent subcellular translocation of a Ca ${ }^{2+}$ /calmodulin-dependent protein kinase produces an autonomous enzyme in Aplysia neurons. J Cell Biol 100: $835-842$.

Schacher S. 1985. Differential synapse formation and neurite outgrowth at two branches of the metacerebral cell of Aplysia in dissociated cell culture. J Neurosci 5: 2028-2034.

Sherff CM, Carew TJ. 2004. Parallel somatic and synaptic processing in the induction of intermediate-term and long-term synaptic facilitation in Aplysia. Proc Natl Acad Sci 101: 7463-7468.

Sossin WS, Schwartz JH. 1992. Selective activation of Ca(2+)-activated PKCs in Aplysia neurons by 5-HT. J Neurosci 12: 1160-1168.

Sugita S, Goldsmith JR, Baxter DA, Byrne JH. 1992. Involvement of protein kinase $\mathrm{C}$ in serotonin-induced spike broadening and synaptic facilitation in sensorimotor connections of Aplysia. J Neurophysiol 68: $643-651$.

Sugita S, Baxter DA, Byrne JH. 1997. Modulation of a cAMP/protein kinase A cascade by protein kinase $\mathrm{C}$ in sensory neurons of Aplysia. J Neurosci 17: $7237-7244$.

Sutton MA, Carew TJ. 2000. Parallel molecular pathways mediate expression of distinct forms of intermediate-term facilitation at tail sensory-motor synapses in Aplysia. Neuron 26: 219-231.

Sutton MA, Masters SE, Bagnall MW, Carew TJ. 2001. Molecular mechanisms underlying a unique intermediate phase of memory in Aplysia. Neuron 31: 143-154.

Toni N, Buchs PA, Nikonenko I, Bron CR, Muller D. 1999. LTP promotes formation of multiple spine synapses between a single axon terminal and a dendrite. Nature 402: 421-425.

Trudeau LE, Castellucci VF. 1995. Postsynaptic modifications in long-term facilitation in Aplysia: Upregulation of excitatory amino acid receptors. J Neurosci 15: 1275-1284.

Villareal G, Li Q, Cai D, Glanzman DL. 2007. The role of rapid, local, postsynaptic protein synthesis in learning-related synaptic facilitation in Aplysia. Curr Biol 17: 2073-2080.

Villareal G, Li Q, Cai D, Fink AE, Lim T, Bougie JK, Sossin WS, Glanzman DL. 2009. Role of protein kinase C in the induction and maintenance of serotonin-dependent enhancement of the glutamate response in isolated siphon motor neurons of Aplysia californica. $J$ Neurosci 29: 5100-5107.

Wang DO, Kim SM, Zhao Y, Hwang H, Miura SK, Sossin WS, Martin KC. 2009. Synapse- and stimulus-specific local translation during long-term neuronal plasticity. Science 324: 1536-1540.

Winder DG, Mansuy IM, Osman M, Moallem TM, Kandel ER. 1998. Genetic and pharmacological evidence for a novel, intermediate phase of long-term potentiation suppressed by calcineurin. Cell 92: $25-37$.

Winer BJ, Brown DR, Kenneth MM. 1991. Statistical principles in experimental design. McGraw-Hill, New York.

Zhao Y, Leal K, Abi-Farah C, Martin KC, Sossin WS, Klein M. 2006. Isoform specificity of PKC translocation in living Aplysia sensory neurons and a role for $\mathrm{Ca}^{2+}$-dependent PKC APL I in the induction of intermediate-term facilitation. J Neurosci 26: 8847-8856.

Received July 21, 2010; accepted in revised form December 6, 2010. 


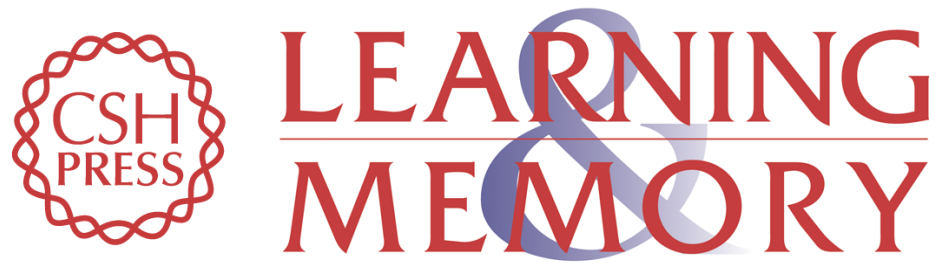

\section{Whereas short-term facilitation is presynaptic, intermediate-term facilitation involves both presynaptic and postsynaptic protein kinases and protein synthesis}

Iksung Jin, Eric R. Kandel and Robert D. Hawkins

Learn. Mem. 2011, 18:

Access the most recent version at doi:10.1101//m.1949711

References This article cites 50 articles, 28 of which can be accessed free at:

http://learnmem.cshlp.org/content/18/2/96.full.html\#ref-list-1

License

Email Alerting Receive free email alerts when new articles cite this article - sign up in the box at the Service top right corner of the article or click here. 